\section{An Interview with Joy Priest}

Joy Priest is the author of HORSEPOWER (Pitt Poetry Series, 2020), winner of the Donald Hall Prize for Poetry. She is the recipient of a 2021 NEA fellowship and a 2019-2020 Fine Arts Work Center fellowship, and has won the 2020 Stanley Kunitz Memorial Prize from APR, and the Gearhart Poetry Prize from The Southeast Review. Her poems have appeared in the Academy of American Poets' Poem-a-Day, The Atlantic, and Virginia Quarterly Review, among others. Her essays have appeared in The Bitter Southerner, Poets \& Writers, ESPN, and The Undefeated, and her work has been anthologized in Breakbeat Poets: New American Poetry in the Age of Hip-Hop, The Louisville Anthology, A Measure of Belonging: Writers of Color on the New American South, and Best New Poets 2014, 2016 and 2019. Joy received her M.F.A. in poetry, with a certificate in Women \& Gender Studies from the University of South Carolina. She is currently a doctoral student in Literature \& Creative Writing at the University of

Houston.

For many writers, a debut collection is really a culmination of years spent on a specific project and their immediate obsessions, while still leading full lives. What was life like in the process of making this book for you? What aspects of your writing and personal life have been altered since its debut?

I wouldn't describe my experience writing Horsepower as "years spent on a specific project" because I didn't know I was working on a specific project until very late. I spent years writing poems. The oldest two poems in Horsepower are 10 years old. So, I can say, retrospectively, that in the span of the last 10 years I wrote poems that would end up in Horsepower, but I also wrote many that would not.

Similarly, I can’t really answer "what life was like" because across those 10 years, which

$$
\text { Page } 78
$$

spanned my twenties - a very dynamic period in anyone's life - what my life was like changed mercurially. I wrote through college, depression, eviction, 9-5̌s, reporting beats, artist collectives, music journalism, waiting tables, obsessions, short-lived romantic entanglements, heartbreak, loss, grief, suicidal periods, depression meds, as well as several geographical relocations, people, body sizes, spirits, dispositions, and identities.

I started submitting the manuscript to first book prizes the penultimate semester of my MFA. I didn't even have a title when I began to submit. It was toward the end of that semester that wrote the title poem, "Horsepower," and realized that was the title of the book. It encompassed all of the book's major conceits. Now, I finally saw a book. Now, I could curate the experience of a book around this concept.

That next summer the manuscript won the Donald Hall Prize - the only prize, coincidentally, that wasn't a first book prize, but which invited manuscripts from poets at all stages (let the record reflect). The book then wasn't published until over a year later, this past September (2020). So, in the time between finishing a manuscript, and going through the publication process of a book, you know, I'm in a much different place than when I was writing the book across my twenties. I hardly think of the poems therein, anymore.

The reception of the book exceeded expectations, selling out of its first run before its release date, and yet the book was also left off all the year-end lists. The demand for new poems from various journals was overwhelming when the book came out, I was doing several virtual readings on Zoom a week. So, in terms of my personal life, I've really had to figure out how to enforce boundaries that protect my writing process so that I'm not just writing on-demand or writing a new poem to answer a solicitation. I don't like that. I put myself on a submission/publishing moratorium after the book came out. So, what changed? The release of any new material as I try to figure out how to write poems again - how to write new individual poems again, as opposed to composing material or revising poems for a manuscript or work-in-progress. Which, I think, involves not writing very much at all, but reading as much as possible. That's how writing-making something out of nothing-always begins for me. Attention and absorption. 
Kentucky, as I've famously heard you say, is known for horses, bourbon, and basketball (I hope I got this right!). All of which tend to lean more toward a more masculine state of socializing or entertainment. What impact might the designation "Tomboy" have on your speaker? How might that particular designation lend itself to your speaker's relationship to gender?

That's interesting. I've never really thought about it quite like that: "masculine state(s) of socializing or entertainment" as particularly characteristic of Kentucky. Growing up, the main sources of entertainment were horses, basketball, boxing, muscle cars, and martial arts films. Also, playing outside, video games, etc. That pretty much sums up my main interests, lol. Maybe it's because my caretaker was a southern man in his sixties, then seventies. Maybe it was my own impulses, which therefore define my Kentucky and the Kentucky of my childhood. I keep trying to write this short story about a girl mechanic. Lol, that's all I got. I don't have a plot or conflict, just like, "I wanna write a story about a Black, southern, female mechanic who only works on cars that were made pre-fuel injection.

Obviously, when it comes to writing a collection of poems that could be described as "narrative" - in that it follows a specific speaker and the events of her trajectory throughout-I don't want to impact her with any easily summed up designations. I hope I wrote a speaker so complex she, instead, requires the reader to understand her without any designations or to understand, newly, those who we designate as such. I guess what I'm saying is, I hope that my speaker complicates gender, and a reader's understanding of who a Black "girl" is, and what her relationship to gender is, particularly in southern spaces that are sort of ruled by the masculine as your question points out-hunting, fishing, guns. I think of Nikky Finney's poem, "Negroes with Guns":

At the knotty rusty screen, the mother who can shoot the first and seconds from out the middle of grasshopper, without browning the grass or decapitating the hop hop, stares out into the field of yellowing pine for sign of insect life or other other.
The trees unwrap. Gunpowder lifts every leaf

into air. .

just behind her

the pig iron smokes.

Throughout Horsepower, we see the speaker engage both the sacred and the profane within the poems. This duality never seems to be outside the scope of the speaker or the lyric. How might this duality be specific to a wayward speaker?

Well, I'm interested in how you see the speaker engaging "both the sacred and the profane within the poems." Examples? How do you see it within the scope of the lyric (in the book)? These are the kind of things that readers see in the work that a writer wasn't explicitly thinking in the poems' construction. I think, what I've come to realize as a debut poet, is that I really want interviewers to point to a poem, a line or two in the poem, and point something like this out and then ask me about it: "See this right here? What were you doing? What were you thinking about?" I've just realized this in the process of being interviewed and thought it might be useful to put forth. The craft of interviewing. .

I suppose what I can say is, rather than a duality, there are just different, perhaps conflicting, ways of looking at wayward.

"That girl is wayward," you might hear someone say about a girl who isn't following a Western colonial sense of etiquette and decorum, which calls for chastity, restraint, and delicateness.

One thing I was interested in with this collection, once I understood the cinematic narrative experience I was trying to curate, was ordering a composition that would capture the Black girl speaker being wayward so as to imply a kind of aspiration - literally, in refusing to stay home and take care of everyone, sacrificing her hopes and desires and dreams in the process, and figuratively, in terms of the fugitivity that Moten and Hartman and Campt and, very specifically for me, Kara Keeling write about. To me, what might be profane in the Enlightenment philosophy that produced the organizing sensibilities of our society (dark = evil; light = innocent) is intentionally made sacred in this book. I was greatly influenced, too, by Keeling's "black femme Page 81 
figure" in her book The Witch's Flight: The Cinematic, the Black Femme, and the Image of Common Sense

Whose common sense are we following?

Keeling writes, "the black femme is a figure that exists on the edge line, that is, the shore line between the visible and the invisible. . Because she often is invisible (but nonetheless present, when she becomes visible, her appearance stops us, offers us time in which we can work to perceive something different or differently" (2). So, in a Western colonial common sense, the black femme figure might appear fugitive in her necessary acts of survival. In fact, this is an idea foundational to the country's Constitution. But, in the common sense of my collection I wanted to work toward a different common sense - the idea that it is okay to be wayward, in fact, in a black femme common sense, it is sacred. Keeling goes on: "Attending to the lines of flight set in motion by (un)successful attempts to contain or circumscribe the black femme within existing epistemological categories provides an opportunity to elucidate the workings of the cinematic and the cinematic processes integral to contemporary racism, sexism, and homophobic violence," and hopefully by attending to those lines I can also avoid, and produce something other than, those racist archetypes inherent in the cinematic and literary tradition of the U.S. Hopefully, I produced a Black femme figure that is visible in her flight, and whose visibility allows us to perceive her waywardness differently.

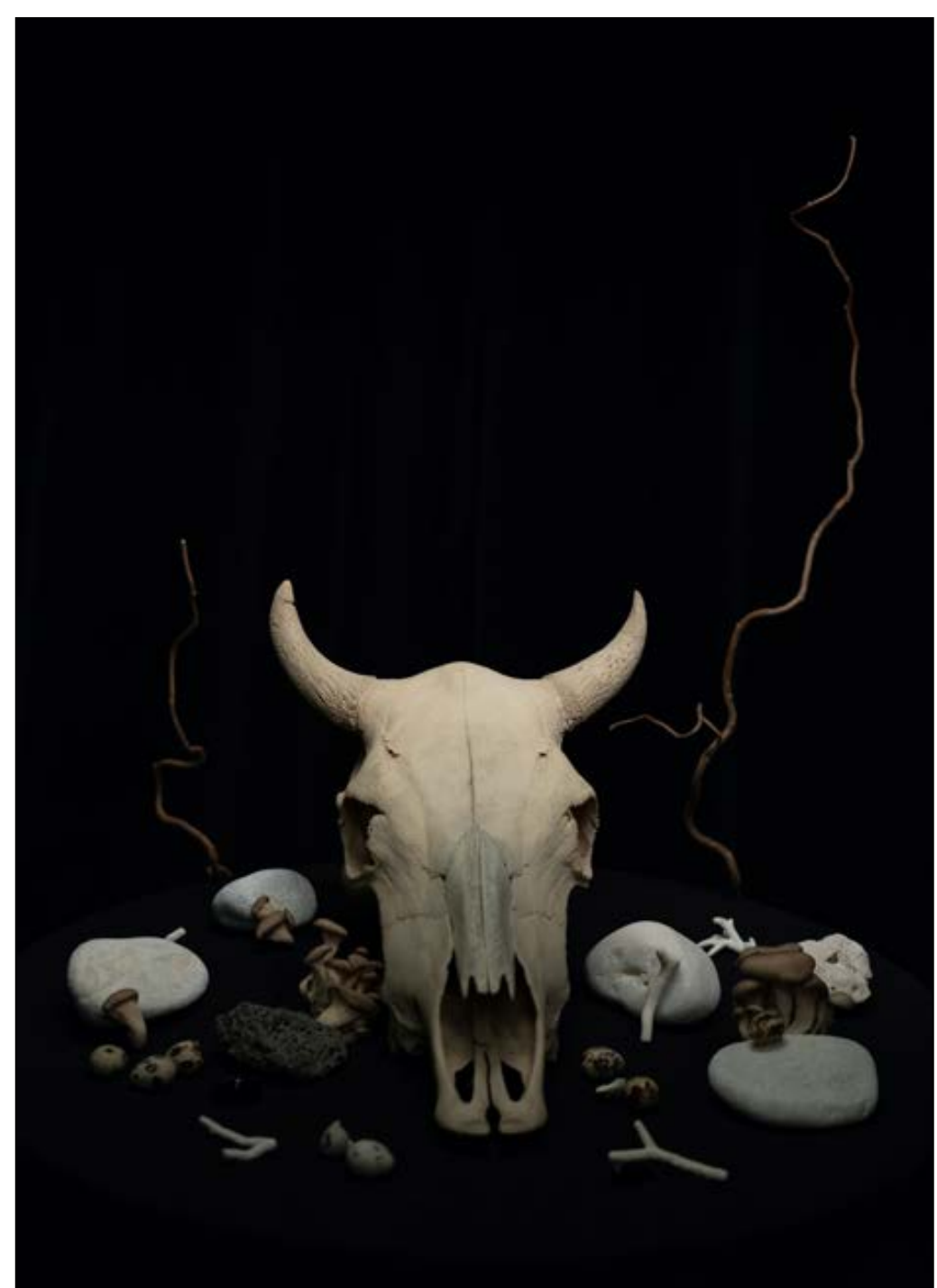

Page 83 